\title{
A data protection perspective on training in the m-health sector
}

\author{
Erik Kamenjasevic, Danaja Fabcic Povse \\ The KU Leuven Centre for IT \& IP Law (CiTiP), Belgium \\ erik.kamenjasevic@kuleuven.be,danaja.fabcic@kuleuven.be
}

The m-health services have brought to the healthcare operators, professionals and patients numerous advantages and, at the same time, opened a door to new cyber threats that might have a significant influence on patient's health and life. Often, cyber-attacks are successful due to a human error and a poor knowledge about the cyber-security. Therefore, deploying innovative trainings of healthcare professionals could lead to a higher level of the cyber-resilience. This paper explores how the healthcare operators may do so in a legally compliant manner by examining the implications of the new General Data Protection Regulation.

Keywords General Data Protection Regulation, cyber security, training, employees' data, legitimate interest, consent

\section{Introduction}

Adoption of mobile health services ( $m$-health) is exponentially growing in the last years due to a broad acceptance and usage of smart phones, tablets and computers. Thus, the healthcare operators (i.e. hospitals) use information technology to increase efficiency of providing healthcare services. They usually impose the usage of such technology to healthcare professionals (i.e. physicians, nurses) in order to deploy information exchange more efficiently (for instance, via electronic health records) as well as to conduct monitoring and to provide the operational support.

Healthcare professionals are the main users and adopters of the technology who often do not have an appropriate knowledge of how to best use such technology. This consequently makes them vulnerable to falling victims of cyber-attacks. Such statement is further supported by the fact that the healthcare sector is the one that is the most frequently targeted by hackers ${ }^{1}$. These cyber-attacks influence patients, the healthcare operators and the healthcare professionals. On the one hand, patient's fundamental right and reasonable interest are to have her health data protected from the unauthorized or unwanted purposes since their disclosure might have a negative impact on her personal and professional life. On the other hand, healthcare operators

\footnotetext{
1 Arndt R Z, In Healthcare, Breach Dangers Come From Inside the House, Modern Healthcare2018, available at: http://www.modernhealthcare.com/article/20180410/NEWS/180419999. For example, more than 20\% of the reported data breaches are due to a human error. At the same time, around $13 \%$ of reported data breaches concerned celebrities' healthcare records that are of particular interest to hackers.
} 
and professionals collect very sensitive personal data, which is among the most intimate information about their patients and whose disclosure or loss might be critical for patient's life. According to the General Data Protection Regulation (the GDPR) ${ }^{2}$, data concerning health belong to special categories of personal data ${ }^{3}$. It is defined as "personal data related to the physical or mental health of a natural person, including the provision of health care services, which reveal information about his or her health status"4. It is crucial that the sensitive data are kept safe and secure during storage, transmission and processing. Article 32 of the GDPR requires that technical and organizational measures are put in place in order to ensure an appropriate level of security of personal data in the course of a data security policy. ${ }^{5}$

Training, as part of organization-wide measures, can raise the level of cybersecurity within an organization ${ }^{6}$ and make an important contribution towards complying with the security requirements. European Cyber Security Agency stated in its recent Healthcare Sector Report ${ }^{7}$ that one of the main needs within the eHealth "entails improving the skills - both technical and behavioral - of the personnel via innovative training techniques that are well received by the (non-IT-expert) workforce. The awareness level in cyber security aspects for all levels of healthcare personnel, e.g., nurses, technicians, administrative personnel and doctors, is an important aspect. The user is most often the weakest link when attacking the target"

Development of the innovative trainings is necessary for several reasons. First, their goal is to protect the patients' data concerning health which consequently means also protecting their reputation and trust in the system, preserving the reputation of the healthcare operator as well as avoiding direct and indirect $\operatorname{costs}^{9}$ that cyber data breaches may cause. Second, due to new threats stemming from the socalled social engineering $2.0^{10}$ where the main cyber-targets are humans instead of ICT domain, a successful training has to be designed in a way that decreases the

\footnotetext{
2 Regulation (EU) 2016/679 of the European Parliament and of the Council of 27 April 2016 on the protection of natural persons with regard to the processing of personal data and on the free movement of such data, and repealing Directive 95/46/EC (General Data Protection Regulation), https://eur-lex.europa.eu/legal-content/EN/TXT/?uri=celex:32016R0679.

${ }^{3}$ Articles 4(15) and 9, Regulation (EU) 2016/679 of the European Parliament and of the Council of 27 April 2016 on the protection of natural persons with regard to the processing of personal data and on the free movement of such data, and repealing Directive 95/46/EC (General Data Protection Regulation), https://eur-lex.europa.eu/legal-content/EN/TXT/?uri=celex:32016R0679.

4 Ibid, Article 4(15).

5 Article 29 Data Protection Working Party, Guidelines on Personal data breach notification under Regulation 2016/679, WP250 p. 6

6 See for example https://www.telegraph.co.uk/connect/small-business/business-networks/bt/how-to-make-staffcybersecurity-aware/, https://securityintelligence.com/how-effective-is-security-awareness-training-for-threat-prevention/.

${ }^{7}$ ECSO, Cyber Security for the Healthcare Sector, WG3, Sectoral Demand, 2018.

8 Ibid, p. 8 .

9 Meisner M, Financial Consequences of Cyber Attacks Leading to Data Breaches in Healthcare sector, CJFA 2017, vol. 6(3), p. 70. In her article, Meisner draws a hypothetical situation regarding financial cost of cyber data breach in Polish hospital. These costs include forensic investigation, breach notification, post-breach patient protection, attorney fees and litigation expenses, regulatory compliance, cybersecurity improvements, loss of reputation and patients churn, other potential costs that would in total amount up to around 2.5 million euros.

${ }^{10}$ See, for example: Ariu D et al, Social Engineering 2.0: A Foundational Work, Proceedings of ACM Computing Frontiers conference, 2017, available at: https://www.dogana-project.eu/images/PDF_Files/ComputingFrontiers17_DAriu_final_.pdf.
} 
impact of the abovementioned phenomenon by empowering the cyber-knowledge of targets. In other words, the training should be designed to focus on the human element of security, across the complete healthcare supply chain, while taking into account the fact that humans are the main means of healthcare operator's exposure to cyber-risks as well as the main barrier to the spread of these risks. Third, the training should be tailored according to the trainee's personality and behavioral traits, hierarchical position, context of training and cybersecurity level. Finally, training's tailoring should take into account a reduction of the prioritized human related cyber-risks and associated risks.

The main question we ask in this chapter is what are the implications of the new GDPR in training healthcare professionals within the context of cybersecurity in adapting to a new $m$-health environment. In order to answer it, we will examine the applicable legal framework on the European Union level. More specifically, we will focus on the novelties introduced by the GDPR which became applicable as of May 25,2018 . We will draw upon the research carried out in the DOGANA and COMPACT projects ${ }^{11}$. We contribute this chapter in order to raise awareness of the legal challenges the healthcare operators and professionals will be facing when deploying the awareness trainings as well as to inform the legal practitioners and policy makers in the field about new challenges imposed by the Regulation.

\section{Legal framework}

\section{When data protection rules apply?}

The GDPR applies to the processing of personal data in the context of the activities of an establishment of a controller ${ }^{12}$ or a processor ${ }^{13}$ in the European Union, regardless of whether the processing takes place in the EU or not ${ }^{14}$. Processing means any operation or set of operations performed on personal data (such as collection, storage, use, erasure, etc. $)^{15}$. Personal data is considered to be any information relating to an identified or identifiable natural person (a data subject) ${ }^{16}$. GDPR makes a distinction between 'normal' personal data and special categories of personal data. Data concerning health belong to the latter group. The level of sensitivity with regards to the two categories of personal data is different, hence,

\footnotetext{
11 Acknowledgment: The research leading to the results presented in this chapter has been partially funded from the European Union's Horizon 2020 Research and Innovation programme, under grant agreements No. 653618 and 740712 (DOGANA and COMPACT, respectively). More information about DOGANA project is available at: https://www.dogana-project.eu/; about COMPACT on https://www.compact-project.eu/en. This paper reflects the authors' views and the Commission is not responsible for any use that may be made of the information it contains.

12 Article 4(7) of the GDPR: “'controller' means the natural or legal person, public authority, agency or other body which, alone or jointly with others, determines the purposes and means of the processing of personal data; where the purposes and means of such processing are determined by Union or Member State law, the controller or the specific criteria for its nomination may be provided for by Union or Member State law".

13 Article 4(8) of the GDPR: “'processor' means a natural or legal person, public authority, agency or other body which processes personal data on behalf of the controller".

14 Articles 2 and 3 of the GDPR.

15 Article 4(2) of the GDPR.

16 Article 4(1) of the GDPR.
} 
different levels of protection apply to each of them. Such distinction becomes relevant especially in the context of $m$-health due to a development of a number of wellbeing and lifestyle apps ${ }^{17}$. Therefore, the definition of the data concerning health foreseen in the GDPR should be interpreted broadly. First, that is the data which concern physical or mental health status of a data subject that is generated in a professional/medical context. This also includes the data that is generated by devices or apps used in a professional medical context irrespective of their qualification as a medical device. Further on, data concerning health is also considered to be the data relating to the health status of a person but is not considered to fall within the former category (i.e. information about smoking and drinking habits or one's membership in a patient support group). This should also include data that is being used in the health related administrative contexts and information about the purchasing of medical products, devices and services ${ }^{18}$. Third, certain data may at first seem as not revealing information about person's health but it may become health related data when "a) collected to - in aggregated form - make assumptions on a person's health, b) are combined with other health related data or c) are transferred to certain third parties ${ }^{19}$. In other words: when personal data (health related or not) are used with the purpose of identifying the health status of an individual, these data will be qualified as health data" 20 . Hence, it is important to highlight that "data which outside of the medical context would maybe not even qualify as personal data will depending on the purposes of the data processing after all be qualified as sensitive data" 21 . Finally, such broad definition of data concerning health goes in line with the Recital 35 of the GDPR.

\section{To whom data protection rules apply?}

In the context of this chapter, a healthcare operator will have a role of a data controller when it determines the purpose and means of the processing of personal data. For instance, this will be the case every time the operator collects and uses information about its patient in order to decide which medication to prescribe. This will also be the case when it processes information about its employees who are participating in the cyber-training. The healthcare operator may as well decide to outsource performing of a training to an external organization who will be, in such case, acting as a processor. Further on, healthcare professionals whether employed by the hospital, or acting as external consultants, are considered employees (and

\footnotetext{
17 See, for example, Martínez-Pérez B et al, Privacy and Security in Mobile Health Apps: A Review and Recommendations, 2014

18 Verhenneman G et al, WITDOM D6.2 - Legal requirements on privacy, data protection and security in WITDOM scenarios, 2016, p 28, available at: http://www.witdom.eu/sites/default/files/witdom/public/content-files/deliverables/D6.2_Legal\%20Requirements_v3.3 final_20161130.pdf.

19 Ibid, p 29.

20 Veale M, Binns R, Fairer machine learning in the real world: Mitigating discrimination without collecting sensitive data, Big Data \& Society, 2017, available at: http://journals.sagepub.com/doi/abs/10.1177/2053951717743530.

21 Verhenneman G et al, WITDOM D6.2 - Legal requirements on privacy, data protection and security in WITDOM scenarios, 2016, p 29, available at: http://www.witdom.eu/sites/default/files/witdom/public/content-files/deliverables/D6.2_Legal\%20Requirements_v3.3 final_20161130.pdf.
} 
data subjects) in the eyes of the data protection legislation ${ }^{22}$. This means that the GDPR applies to them in its entirety; nevertheless, under its Article 88, Member States may regulate certain aspects of data protection in an employment context. Such rules must safeguard the data subject's human dignity, legitimate interests and fundamental rights, especially regarding transparency, transfers of personal data, and monitoring systems put in place. ${ }^{23}$ For example, under the new German data protection act, ${ }^{24}$ employees' personal data may be processed for employment-related purposes where necessary for hiring decisions or, after hiring, for carrying out or terminating the employment contract or to exercise or satisfy rights and obligations of employees' representation laid down by law or by collective agreements or other agreements between the employer and staff council. ${ }^{25}$

\section{Data protection principles}

Data protection principles constitute the guidance for striking the right balance between the data protection of the employees participating in the training and the protection of the company's (cyber) security. The principles have not changed significantly with respect to prior rules in the Data Protection Directive (the DPD) ${ }^{26}$. Namely, lawfulness, fairness and transparency principle, purpose limitation principle, data minimization principle, accuracy, storage limitation, and integrity and confidentiality principle are embodied in Article 5(1) of the GDPR and they should apply to any information concerning identified or identifiable person ${ }^{27}$.

In the training context, special attention is given to the principles of purpose limitation principle and data minimization (both known under the umbrella name of the data quality principle). Purpose limitation principle requires from data controllers to collect the data for specific, explicit and legitimate purposes and not to process the data in a manner that is incompatible with those purposes (unless one of the exception applies). Data minimization principle states that personal data must be adequate, relevant and limited to what is necessary in relation to the purposes for which they are processed.

Main innovative step of the GDPR concerns the principle of accountability established by Article 5(2) and further detailed in Article 24 of the GDPR. It requires controllers to put in place "appropriate technical and organizational measures to ensure and to be able to demonstrate that the processing meets the requirements" 28 of the law. In fact, this principle requires from a data controller to adopt a proactive

\footnotetext{
22 Article 29 Data Protection Working Party, Opinion 2/2017 on data processing at work, adopted on 8 June 2017, 17/EN, WP249, p. 4, available at https://ec.europa.eu/newsroom/article29/document.cfm?action=display\&doc id=51030.

23 The implementation of specific rules is slow. An overview (from December 2017) is available here: http://ec.europa.eu/transparency/regexpert/index.cfm?do=groupDetail.groupMeetingDoc\&docid=9350, and here (from May 2018): https://iapp.org/resources/article/eu-member-state-gdpr-implementation-laws-and-drafts/.

24 Bundesschutzgesetz, for English translation see https://iapp.org/media/pdf/resource center/Eng-trans-Germany-DPL.pdf.

25 Section 26(1) of the Federal Data Protection Act.

26 Directive 95/46/EC of the European Parliament and of the Council of 24 October 1995 on the protection of individuals with regard to the processing of personal data and on the free movement of such data

27 Recital 26 of the GDPR

28 Article 24 of the GDPR.
} 
role in ensuring protection of personal data through appropriate technical and organizational measures and to be able to demonstrate compliance with the data protection requirements. In order to implement this principle successfully, controllers are recommended to adopt internal data protection policies and to promote cyber security awareness initiatives among their employees, for example through programs, trainings, and procedures that will help integrating employees' cyber security awareness into the process of corporate culture.

\section{Security measures and security policies}

Similar to Article 17 of the DPD, GDPR requires controllers and processors to implement technical and organizational measures to ensure a level of security of personal data appropriate to the risk such as loss or unauthorized access, destruction, use, modification or disclosure of the data. Article 32 of the GDPR suggests the security measures that might be considered 'appropriate to the risk', such as the pseudonymization and encryption of personal data; the ability to ensure the ongoing confidentiality, integrity, availability and resilience of processing systems and services; the ability to ensure the availability and access to personal data in a timely manner in the event of a physical or technical incident; a process for regular testing, assessing and evaluating the effectiveness of technical and organizational measures for ensuring the security of the processing. Such list of measures is not exhaustive and a controller still has a duty to identify the adequate measures to put in place since the controller itself is in the best position to judge what would be an appropriate level of security while at the same time taking into account the state of the art and costs of their implementation. Finally, under the principle of security of processing, controllers have a duty to notify any breach of personal data to the supervisory authority and in certain cases to the data subject as well ${ }^{29}$.

Company security policies consist of a combination to manage processes, people and technologies in order to implement robust security values and to protect confidentiality, integrity and availability of information and other valuable assets ${ }^{30}$. Policies, procedures and training information need to be developed and documented in order to be easily accessible to all employees. Such documentation should explain the goals and the requirements (concerning but not limited to cyber-security), specifications of the technology and services that will be used and instructions on how to use devices/services, such as m-health apps. The company should take a proactive role and focus on the development of information policies concerning (cyber)security as well as policies based on the solutions and techniques that will be implemented once the training has been deployed ${ }^{31}$. Following security policies should be carefully considered and implemented when deploying the training within the healthcare operators ${ }^{32}$ :

\footnotetext{
${ }^{29}$ Articles 33 and 34 of the GDPR.

$30 \mathrm{~S}$. Wu, A legal guide to enterprise mobile device management, ABA Section of Science \& Technology Law, 2013 , p. 50-60, ISO/IEC27002:2013, Information technology. Security techniques. Code of practice for information security controls, 2013

31 Vogiatzoglou P et. al, DOGANA D5.3 Legal and ethical conditions for cautious organisations, 2017.

32 Custodio F, DOGANA D5.2 - Legal Requirements for Privacy by Design, 2016, pp. 10-12, available at: https://www.dogana-project.eu/images/PDF_Files/D5.2-Legal-Requirements-for-Privacy-by-Design.pdf.
} 
- Trainees must be fully informed through the corporate security policies about the possibility of conducting the training.

- All data must be traceable at any moment and it must be possible to identify in a human-readable report all personal data about an individual and the identity of the owner of data stored within the system.

- The system must allow deleting personal data of an individual. Data that is collected but not used for the training purposes must be deleted immediately.

- Data stored in a system may be kept according to the retention times matching national legal requirements where the training is taking place.

- Only publicly available, non-sensitive, professional data about trainees should be collected. All other data that cannot be categorized as professional must be discarded.

- All operations must be logged with the information about the date, time, location, system, user and action performed on data. Logs must be kept in order to conduct an independent verification of all actions performed on personal data through all the processing stages.

- System used within the training scheme for personal data storage and processing must be in line with ISO 27001 standard or another third-party verification scheme.

- Data controller has to be appointed within the organization deploying the training who has to provide answers to queries of individuals about their information.

- Access to personal data within the training must be subject to user authentication. Access level should be allowed only to authorized individuals.

- Personal data and the training results must be anonymized as soon as the state of the art technique allows it.

\section{Playing by the rules}

Training deployment involves personal data processing in several phases. First, participants are chosen from among the employees and a specific type of (cyber-awareness) training is ascribed to them, which can lead to questions about profiling and automated decision-making. Second, employees' consent is rarely free, hence, this raises questions about appropriate legal grounds. Third, under the GPDR, the participants should be able to exercise the rights they have as data subjects, in a training context.

Not necessarily all the healthcare professionals within one healthcare operator will be trained. In the recruitment process, certain employees will be chosen and we will refer to them as 'participants', 'trainees', 'employees' and 'healthcare professionals' interchangeably. 


\section{Choice of participants and appropriate training}

Employees' cyber-habits may vary due to their different personalities, human characteristics and traits ${ }^{33}$. For example, students majoring in engineering tend to have more secure passwords than humanities majors, and extroverts are more likely to lock their devices than introverts. Due to those different factors, not everyone responds as effectively to a certain type of training ${ }^{34}$. Therefore, participants are categorized and trained accordingly. This is referred to as profiling ${ }^{35}$. The GDPR defines profiling in Article 4(4) as: "any form of automated processing of personal data consisting of the use of personal data to evaluate certain personal aspects relating to a natural person, in particular to analyse or predict aspects concerning that natural person's performance at work, economic situation, health, personal preferences, interests, reliability, behaviour, location or movements". Three elements are important for this definition: (1) there must be automated processing, (2) that is carried out on personal data, and (3) such processing is carried out in order to evaluate personal aspects about a natural person ${ }^{36}$. It is important to point out that automated processing does not mean that the processing is done exclusively by a computer - on the contrary, even if a human is involved in the categorization activities, they still fall under the definition. Categorization as such falls under this provision, even if there is no further inference or correlation involved ${ }^{37}$. As stated in Recital 72 of the GDPR, profiling is subject to the rules governing the processing of personal data, such as the legal grounds for processing or data protection principles. Therefore, when profiling physicians for training, the healthcare operator must ensure that its actions are compliant with the GDPR. For example, when using the already available data on employees' personal characteristics, compliance with the purpose limitation principle must be assessed. This means that the new purpose, i.e. profiling for training objectives, must be compatible with the original purpose, for which the data had been provided, for example a personality test during the recruitment process ${ }^{38}$. Several criteria need to be taken into account to assess whether the secondary purpose is compatible with the original one; inter alia, whether there is an appropriate relationship between two purposes and whether the employee could have expected such further processing ${ }^{39}$.

\footnotetext{
33 Gratian M., Bandi S., Cukier M., Dykstra J., Ginther A., Correlating human traits and cyber security behavior intentions, computers \& security 73, 2018, pp. 345-358; Cain A., Edwards M., Still J., An exploratory study of cyber hygiene behaviors and knowledge, Journal of Information Security and Applications, Volume 42, 2018, http://www.sciencedirect.com/science/article/pii/S2214212618301455.

34 G Gratian M., Bandi S., Cukier M., Dykstra J., Ginther A., Correlating human traits and cyber security behavior intentions, computers \& security 73, 2018, pp. 345-358.

35 Article 29 Data Protection Working Party, Guidelines on Automated individual decision-making and Profiling for the purposes of Regulation 2016/679.

36 Ibid, p. 6.

${ }^{37}$ Unlike the prohibition of automated decision-making, which applies solely to purely automated processes, without human intervention.

38 WP29 Opinion 03/2013 on purpose limitation, 2 April 2013

39 Ibid.
} 
Furthermore, the categorization of employees should not be done according to discriminatory criteria. Definitions of discriminatory criteria vary: for example, disparate treatment based on an individual's race, color, religion, sex, or national origin, according to the US Civil Rights Act ${ }^{40}$; the European Convention on Human Rights prohibits discrimination, based on any ground such as sex, race, colour, language, religion, political or other opinion, national or social origin, association with a national minority, property, birth or other status ${ }^{41}$; the proposed Equal Treatment Directive of 2008 mandates equal treatment outside the labor market, irrespective of age, disability, sexual orientation or religious belief. Discrimination is often mentioned together with unequal or disparate treatment, based on the above criteria ${ }^{42} 43$.

Categorisation can be carried out manually, by a human, or by a machine using an algorithm, or a combination of both, for example when the human relies on the decision made by the machine. While humans are fallible and biased, being treated solely by a machine in a 'computational manner' - in other words, as nothing but a number, is considered dehumanising in Europe ${ }^{44}$. Moreover, while profiling and categorization promote accuracy in decisions, improved risk management and fraud prevention $^{45} 46$, they also perpetuate discrimination and stereotypes. Even if there is no original intent to discriminate, the effects can still materialize when the algorithm learns to discriminate based on the data it has been fed with ${ }^{47}$. Hence, as the selection process is based on categorisation, certain safeguards should be put in place. For example, the employees should be aware of when and how the categorisation works in order to reduce the knowledge asymmetry between them and the decision-

\footnotetext{
40 Title VII of the Civil Rights Act of 1964. See also Michael Evan Gold, Griggs' Folly: Essay on the Theory, Problems, and Origin of the Adverse Impact Definition of Employment Discrimination and a Recommendation for Reform, 7 Indus. Rel. L.J. 429 (1985)

41 See European Convention on human rights and its Protocol No. 2: https://www.echr.coe.int/Documents/Convention_ENG.pdf.

42 For example, in European Union Agency for Fundamental Rights, Fundamental Rights Report 2018.

43 One of the most debated criteria in Europe is gender. The European Court of Human Rights has recently confirmed that "the advancement of gender equality is today a major goal in the member States of the Council of Europe" and that justification for disparate treatment based on gender must pursue a legitimate aim and be justified with "very weighty reasons". A new Directive, addressing inequality and mandating equal treatment even between individuals, i.e. in the workplace, has been proposed by the European Commission. However, it has been debated for the last ten years and is currently being blocked by the Council. In that regard see, for example, Emel Boyraz v. Turkey, ECtHR judgment of December 2 2014, §54, and Konstantin Markin v. Russia, ECtHR Grand Chamber judgment of 22 March 2012, 127.

44 Jones, M.-L., A Right to a Human in the Loop, Social Studies of Science 2017, Vol. 47(2) pp. 216-239.

45 Le-Khac NA., Markos S., Kechadi MT. (2010) Towards a New Data Mining-Based Approach for Anti-Money Laundering in an International Investment Bank. In: Goel S. (eds) Digital Forensics and Cyber Crime. ICDF2C 2009. Lecture Notes of the Institute for Computer Sciences, Social Informatics and Telecommunications Engineering, vol 31. Springer, Berlin, Heidelberg.

46 Kamp, Meike; Körffer, Barbara; Meints, Martin. Profiling of Customers and Consumers - Customer Loyalty Programmes and Scoring Practices, in: Hildebrandt, Mireille; Gutwirth, Serge (editors). Profiling the European Citizen: Cross-Disciplinary Perspectives, New York: Springer, 2008, pp. 201-215

47 Schermer B, The limits of privacy in automated profiling and data mining, Computer Law \& Security Report 27(1):45-52, February 2011.
} 
maker ${ }^{48}$, transparency should be ensured and meaningful information given ${ }^{49}$ in order to comply with the information requirements set out in Articles 13 and 14 of the GDPR.

\section{Ensuring transparency}

Participants involved in training must be notified about the processing of their personal data, their rights as data subjects, as well as other information, provided for in the Articles 13, 14 and 15 of the GDPR. These three articles provide for provision of information to data subjects in three different situations. In the training context, personal data can come directly from the participants, for example when their improving skills are being monitored; or from a different source, for example from the HR department, which provides the trainers with the information on what kind of personality traits the participants have, or from their publically available social media profiles. Alternatively, the trainees can require access to their own personal data from the healthcare operator about the training they are undergoing, according to the Article 15 of the GDPR. In either scenario, the information must be provided in a clear and concise manner, in an easily understandable language. Infographics are often used since they are easier to read than a wall of text. Namely, the list of information the controller must provide is long and covers information, such as categories of data processed, the contact details of the data protection officer, time limitation for deletion of data, the existence of automated decision-making, etc. ${ }^{50}$

Whether or not the information duties include the data subject's right to an explanation $^{51}$ through ensuring transparency, the healthcare operator should also make sure the trainees know why they were chosen to participate and why they were assigned to a specific type of training. This information must be given either at the time of collection of personal data directly from the trainee. If the data come from a different source, then it must be done within a month of obtaining them. The notification is easily done before the training starts, and kept up throughout the training. Moreover, the transparent procedure should enable the trainees to exercise their rights as data subjects ${ }^{52}$. Since healthcare operators process sensitive personal data in the course of their business, they are required to, according to Article 37 of the GDPR, appoint a data protection officer who acts as a contact point for employees

\footnotetext{
48 Gutwirth, Serge; Hildebrandt, Mireille. Some Caveats on Profiling, in: Gutwirth, Serge (Editor); Poullet, Yves (Editor); De Hert, Paul (Editor). Data protection in a profiled world, 2010, Dordrecht: Springer, pp. 31-41.

49 See among others: Van der Hof, Prins, Personalisation and its Influence on Identities, Behaviour and Social Values; 41. Selbst A., Powles J., Meaningful information and the right to explanation, International Data Privacy Law, Volume 7, Issue 4, 1 November 2017.

50 See Art. 13, 14 and 15 of the GDPR, and the Article 29 Data Protection Working Party, Guidelines on Transparency under Regulation 2016/679, WP260rev.01, adopted on 29 November 2017 and as last revised and adopted on 11 April 2018.

51 Due to inconsistencies and unclear wording, it is contentious whether the right to an explanation exists in the GDPR. See: Selbst A., Powles J., Meaningful infor-mation and the right to explanation, International Data Privacy Law, Volume 7, Issue 4, 1 November 2017, Pages 233-242, https://doi.org/10.1093/idpl/ipx022; see also Wachter S., Mittelstadt B., Floridi L., Why a right to explanation of au-tomated decision-making does not exist in the General Data Protection Regula-tion, International Data Privacy Law, 2017, Vol. 7, No. 2.

52 See Article 29 Data Protection Working Party, Guidelines on Transparency under Regulation 2016/679, WP260rev.01, adopted on 29 November 2017 and as last revised and adopted on 11 April 2018.
} 
and other data subjects (especially the patients) and facilitates the exercise of their rights. Therefore, it is crucial that the DPO's name and contact details are communicated to the participants in due course of the training ${ }^{53}$.

\section{Legal grounds}

\section{a) Consent}

Under the GDPR, consent must be freely given, specific, informed and unambiguous in order to be valid ${ }^{54}$. This means giving the trainee a genuine choice in giving or denying consent to participation in training as well as control over the processing. However, due to power dynamics and lack of power balance between the employer and the employee, and the likelihood of the employees facing prejudice when they refuse to give consent, consent cannot be given freely and cannot be relied upon as legal grounds in the employment context ${ }^{55}$. Moreover, training can also be provided in the form of fake phishing attacks against healthcare professionals. Since this type of training must be as close to a real phishing attack, it would be unrealistic to deploy a phish against an aware (and consenting) target. Participants may be told they are taking part in some kind of a study, but are instead attacked with a phishing email. In research, this technique is called deception ${ }^{56}$. Deception can cause participants to feel distressed, humiliated and lose their trust in the employer, who seems to be sending them risky emails. Therefore, it is very important that the participants are fully debriefed about the reasons behind the phishing attack after it has been carried out; as well as given an opportunity to opt-out, thus giving effect to the right to object to processing, enshrined in Article 21 of the GDPR ${ }^{57}$.

b) Alternatives: legitimate interest and compliance with the legal obligation

Alternative legal grounds can be found in paragraphs (c) and (f) of Article 6 of the GDPR. Namely, processing is lawful if it is necessary for compliance with a legal obligation to which the healthcare operator is subject, or if processing is necessary for the purposes of the legitimate interests pursued by the healthcare operator. In both instances, processing must be necessary - the goal (ensuring cybersecurity) cannot be reached with a less invasive measure, without processing personal data (or, in different words, without training the employees). However, due to human element's role, it would not be feasible to implement cyber security measures

\footnotetext{
53 Article 29 Data Protection Working Party, Guidelines on data protection officers (DPO), WP243, 13 December 2016.

54 See Article 4(11), Article 6(1)(a) and Article 7 of the GDPR.

55 Article 29 Data Protection Working Party Opinion 2/2017 on data processing at work, adopted on 8 June 2017 , 17/EN, WP249, and Guidelines on Consent under Regulation 2016/679, [1]WP259 rev.01, adopted on 28 November 2017 and as last revised and adopted on 10 April 2018.

${ }^{56}$ Finn, P, Jakobsson, M, Designing ethical phishing experiments, IEEE Technology and Society Magazine, Spring 2007, Vol.26(1), pp 46-58.

57 Resnik D.B., Finn P.R., Ethics and phishing experiments, Science and Engineer-ing Ethics (2018) 24: 1241. https://doi.org/10.1007/s11948-017-9952-9.
} 
without training the employees. Nonetheless, where two or more alternative trainings are available, the less intrusive one should be chosen, so long as it contributes to the objective.

Legitimate interests as such are not defined in the GDPR. Nevertheless, the GDPR provides few examples of situations that count as legitimate interests. This is the case when the data subject is a client or in the service of the controller and when the former can reasonably expect at the time and in the context of the collection of the personal data that processing for that purpose may take place ${ }^{58}$. More specifically, running and maintaining a website ${ }^{59}$, preventing fraud, direct marketing purposes, processing employees' data within a group of undertakings for internal administrative purposes, as well as for ensuring network and information security $^{60}$, fall under the notion of legitimate interests. However, when ensuring network and information security, the processing must only be done to the extent strictly necessary and proportionate (for example, monitoring access to an email address but not its correspondence ${ }^{61}$ ). Reliance on legitimate interests of the controller comes with one more caveat; if the data subject's fundamental rights and interests outweigh those of the controller, then the latter cannot rely on this legal basis. Since training healthcare professionals to adapt to a new m-health environment can drive down the costs and provide better service to the patient, such interests can be considered legitimate in the sense of the GDPR. After all, prominent international and regional treaties and documents, such as the constitution of the World Health Organisation and the European Social Charter ${ }^{62}$, contain references to the health-related rights and the need to provide the highest possible standard of health(care) attainable. It is not very likely that a single healthcare professional's fundamental rights and freedoms would outweigh a common human concern; nonetheless, this balance should be continually assessed ${ }^{63}$.

Alternatively, the healthcare operator can rely on processing being necessary for compliance with a legal obligation to which it is subject. Such a legal obligation and the purpose of processing can be found on European Union level or in national ${ } \mathrm{aw}^{64}$. In European Union law, the Network and Information Systems Directive (the NIS Directive) $)^{65}$ provides that operators of essential services, to whom healthcare

\footnotetext{
58 Recital 47 of the GDPR.

59 Court of Justice of the European Union, C-582/14, Patrick Breyer v. Bundesrepublik Deutschland.

60 Recitals 47 and 48 of the GDPR.

61 IAPP, Guidance on the use of Legitimate Interests under the EU General Data Protection Regulation, https://iapp.org/media/pdf/resource_center/DPN-Guidance-A4-Publication.pdf.

62 See Part I. 11 of the ESC: Everyone has the right to benefit from any measures enabling him to enjoy the highest possible standard of health attainable.

63 IAPP suggest a LIA - legitimate interests assessment, and provide a template. See https://iapp.org/media/pdf/resource center/DPN-Guidance-A4-Publication.pdf.

64 Art. 6(3) of the GDPR.

65 Directive (EU) 2016/1148 of the European Parliament and of the Council of 6 July 2016 concerning measures for a high common level of security of network and information systems across the Union, available at: https://eurlex.europa.eu/legal-content/EN/TXT/?toc=OJ:L:2016:194:TOC\&uri=uriserv:OJ.L_.2016.194.01.0001.01.ENG.
} 
operators can belong under certain conditions ${ }^{66}$, must take appropriate and proportionate technical and organisational measures in order to counter the risks against the networks. Training healthcare professionals and raising awareness of cybersecurity can help in complying with this requirement, as the Recital 38 of the Directive suggests. However, the processing of personal data must not go beyond what is necessary to attain the goal pursued, otherwise this cannot be considered as valid legal grounds.

\section{Conclusion}

Healthcare operators play a highly important role in our society. Central to them are the patients whose data is collected, used and processed by healthcare professionals every day. At the same time, those who are dealing with the sensitive data the most are considered to be the weakest link in the organizational cyber-security chain. As a consequence, the healthcare professionals are considered to be the main facilitator of cyber data breaches that may have a significant impact on patients' private and personal life. Meanwhile, if trained appropriately they can act as the main shield against the cyber-threats.

Traditional ways of ensuring cybersecurity within the organization do not pay enough attention to the human factor. One of the solutions to improve the cyberknowledge of the healthcare professionals is to provide them with innovative trainings tailored according to their personal traits and habits in order to raise their awareness about cyber-threats, consequences that cyber-attacks may provoke, how to timely detect them and finally how not to fall victims to them. By deploying the cyber-training of its professionals, a healthcare operator may be in a position to better understand the current threats against it by measuring the actual risk and to find potentially effective and tailored countermeasures to mitigate the cyber-risk.

66 Healthcare operators are subject to the NIS directive if they meet the criteria, laid down in its Article 5, and those in point (g) of Article 3 of Directive 2011/24/EU. 


\section{References}

1. Ariu D et al, Social Engineering 2.0: A Foundational Work, Proceedings of ACM Computing Frontiers conference, 2017, available at: https://www.dogana-project.eu/images/PDF Files/ComputingFrontiers17 DAriu final .pdf.

2. Arndt R Z, In Healthcare, Breach Dangers Come From Inside the House, Modern Healthcare2018, available at: http://www.modernhealthcare.com/article/20180410/NEWS/180419999. For example, more than $20 \%$ of the reported data breaches are due to a human error. At the same time, around $13 \%$ of reported data breaches concerned celebrities' healthcare records that are of particular interest to hackers.

3. Article 29 Data Protection Working Party, Guidelines on Automated individual decision-making and Profiling for the purposes of Regulation 2016/679

4. Article 29 Data Protection Working Party, Opinion 03/2013 on purpose limitation, 2 April 2013

5. Article 29 Data Protection Working Party, Guidelines on Transparency under Regulation 2016/679, WP260rev.01, adopted on 29 November 2017 and as last revised and adopted on 11 April 2018.

6. Article 29 Data Protection Working Party, Guidelines on data protection officers (DPO), WP243, 13 December 2016.

7. Article 29 Data Protection Working Party, Guidelines on Consent under Regulation 2016/679, [1]WP259 rev.01, adopted on 28 November 2017 and as last revised and adopted on 10 April 2018.

8. Article 29 Data Protection Working Party, Guidelines on Personal data breach notification under Regulation 2016/679, WP250 p. 6

9. Article 29 Data Protection Working Party, Opinion 2/2017 on data processing at work, adopted on 8 June 2017, 17/EN, WP249, available at https://ec.europa.eu/newsroom/article29/document.cfm?action=display\&doc id $=51030$.

10. Bundesschutzgesetz, for English translation see https://iapp.org/media/pdf/resource center/Eng-trans-GermanyDPL.pdf

11. Cain A., Edwards M., Still J., An exploratory study of cyber hygiene behaviors and knowledge, Journal of Information Security and Applications, Volume 42, 2018, http://www.sciencedirect.com/science/article/pii/S2214212618301455

12. Custodio F, DOGANA D5.2 - Legal Requirements for Privacy by Design, 2016, pp. 10-12, available at: https://www.dogana-project.eu/images/PDF_Files/D5.2-Legal-Requirements-for-Privacy-by-Design.pdf.

13. Court of Justice of the European Union, Case C-210/16, Unabhängiges Landeszentrum für Datenschutz SchleswigHolstein v. Wirtschaftsakademie Schleswig-Holstein GmbH, 05.06.2018.

14. Court of Justice of the European Union, case C-582/14, Patrick Breyer v. Bundesrepublik Deutschland

15. Directive 95/46/EC of the European Parliament and of the Council of 24 October 1995 on the protection of individuals with regard to the processing of personal data and on the free movement of such data.

16. Directive (EU) 2016/1148 of the European Parliament and of the Council of 6 July 2016 concerning measures for a high common level of security of network and information systems across the Union

17. ECSO, Cyber Security for the Healthcare Sector, WG3, Sectoral Demand, 2018.

18. Emel Boyraz v. Turkey, ECtHR judgment of December $22014, \S 54$

19. European Union Agency for Fundamental Rights, Fundamental Rights Report 2018

20. European Convention on Human Rights

21. European Social Charter

22. European Commission, GDPR Implementation: State of play in the Member States - on 6 December 2017, http://ec.europa.eu/transparency/regexpert/index.cfm?do=groupDetail.groupMeetingDoc\&docid=9350

23. European Parliament, Legislative train: Anti-discrimination directive, http://www.europarl.europa.eu/legislativetrain/theme-area-of-justice-and-fundamental-rights/file-anti-discrimination-directive

24. Finn, P, Jakobsson, M, Designing ethical phishing experiments, IEEE Technology and Society Magazine, Spring 2007, Vol.26(1), pp 46-58.

25. Gold M., Griggs' Folly: Essay on the Theory, Problems, and Origin of the Adverse Impact Definition of Employment Discrimination and a Recommendation for Reform, 7 Indus. Rel. L J. 429 (1985)

26. Gratian M., Bandi S., Cukier M., Dykstra J., Ginther A., Correlating human traits and cyber security behavior intentions, computers \& security 73 (2018) 345-358

27. Gutwirth, Serge; Hildebrandt, Mireille. Some Caveats on Profiling, in: Gutwirth, Serge (Editor); Poullet, Yves (Editor); De Hert, Paul (Editor). Data protection in a profiled world, 2010, Dordrecht: Springer, pp. 31-41.

28. How to make your staff cybersecurity aware, https://www.telegraph.co.uk/connect/small-business/business-networks/bt/how-to-make-staff-cybersecurity-aware/

29. How Effective Is Security Awareness Training for Threat Prevention?, https://securityintelligence.com/how-effective-is-security-awareness-training-for-threat-prevention/

30. IAPP, Guidance on the use of Legitimate Interests under the EU General Data Protection Regulation, https://iapp.org/media/pdf/resource center/DPN-Guidance-A4-Publication.pdf

31. IAPP, EU Member State GDPR Implementation Laws and Drafts, https://iapp.org/resources/article/eu-memberstate-gdpr-implementation-laws-and-drafts

32. Jones, M.-L., A Right to a Human in the Loop, Social Studies of Science 2017, Vol. 47(2) 216-239. 
33. Kamp M, Körffer B, Meints M, Profiling of Customers and Consumers - Customer Loyalty Programmes and Scoring Practices, in: Hildebrandt, Mireille; Gutwirth, Serge (editors). Profiling the European Citizen: Cross-Disciplinary Perspectives, New York: Springer, 2008, pp. 201-215

34. Konstantin Markin v. Russia, ECtHR Grand Chamber judgment of 22 March 2012, § 127

35. Le-Khac NA., Markos S., Kechadi MT. (2010) Towards a New Data Mining-Based Approach for Anti-Money Laundering in an International Investment Bank. In: Goel S. (eds) Digital Forensics and Cyber Crime. ICDF2C 2009. Lecture Notes of the Institute for Computer Sciences, Social Informatics and Telecommunications Engineering, vol 31. Springer, Berlin, Heidelberg

36. Meisner M, Financial Consequences of Cyber Attacks Leading to Data Breaches in Healthcare sector, CJFA 2017, vol. 6(3), p. 70.

37. Martínez-Pérez B et al, Privacy and Security in Mobile Health Apps: A Review and Recommendations, 2014

38. Regulation (EU) 2016/679 of the European Parliament and of the Council of 27 April 2016 on the protection of natural persons with regard to the processing of personal data and on the free movement of such data, and repealing Directive 95/46/EC (General Data Protection Regulation), https://eur-lex.europa.eu/legal-content/EN/TXT/?uri=celex:32016R0679.

39. Resnik D.B., Finn P.R., Ethics and phishing experiments, Science and Engineering Ethics (2018) 24: 1241 https://doi.org/10.1007/s11948-017-9952-9

40. Schermer B, The limits of privacy in automated profiling and data mining, Computer Law \& Security Repor 27(1):45-52, February 2011.

41. Selbst A., Powles J., Meaningful information and the right to explanation, International Data Privacy Law, Volume 7, Issue 4, 1 November 2017, Pages 233-242, https://doi.org/10.1093/idpl/ipx022

42. S. Wu, A legal guide to enterprise mobile device management, ABA Section of Science \& Technology Law, 2013, p. 50-60, ISO/IEC27002:2013, Information technology. Security techniques. Code of practice for information security controls, 2013

43. Title VII of the Civil Rights Act of 1964

44. Veale M, Binns R, Fairer machine learning in the real world: Mitigating discrimination without collecting sensitive data, Big Data \& Society, 2017, available at: http://journals.sagepub.com/doi/abs/10.1177/2053951717743530.

45. Verhenneman G et al, WITDOM D6.2 - Legal requirements on privacy, data protection and security in WITDOM scenarios, 2016, available at: http://www.witdom.eu/sites/default/files/witdom/public/content-files/deliverables/D6.2 Legal\%20Requirements v3.3 final 20161130.pdf.

46. Van der Hof, Simone; Prins, Corien. Personalisation and its Influence on Identities, Behaviour and Social Values, in: Hildebrandt, Mireille, Gutwirth, Serge (editors). Profiling the European Citizen: Cross-Disciplinary Perspectives, New York: Springer, 2008

47. Vogiatzoglou P et. al, DOGANA D5.3 Legal and ethical conditions for cautious organisations, 2017.

48. Wachter S., Mittelstadt B., Floridi L., Why a right to explanation of automated decision-making does not exist in the General Data Protection Regulation, International Data Privacy Law, 2017, Vol. 7, No. 2. 